\title{
DETERMINANTS OF ATTITUDES TOWARD AFFIRMATIVE ACTION IN A SWISS SAMPLE
}

\author{
Franciska Krings \\ University of Lausanne \\ Franziska Tschan \\ Sophie Bettex \\ University of Neuchâtel
}

\begin{abstract}
Swiss employees were surveyed to assess knowledge of and attitudes toward different types of affirmative action programs (AAPs) for women. Findings show that knowledge of AAPs was limited and AAPs were most frequently associated with child care measures. Attitudes toward opportunity enhancement programs, especially toward child care, were more positive than toward preferential selection and positive discriminatory programs. Women held more positive attitudes toward AAPs. However, for some attitudes, gender differences were entirely mediated by symbolic prejudice toward working women. Independently of gender, symbolic prejudice was a key predictor of all attitudes. Measures of selfview (self-esteem and gender self-concept) were largely unrelated to attitudes toward AAPs. Implications for research and organizations are discussed.
\end{abstract}

KEY WORDS: affirmative action; attitudes; gender; prejudice; self-view.

Affirmative action programs (AAPs) for women and minorities have been the subject of heated debates. In the United States, affirmative action is one of the most controversial policy issues (Crosby, Iyer, Clayton, \& Downing, 2003). In European countries, affirmative action is less a focus of public attention, but nevertheless a highly controversial issue. Proponents of AAPs consider them necessary measures to redress past and prevent future discrimination. Opponents argue that AAPs are unjust because preferential treatment based on group membership is inherently unfair; moreover, they are harmful to the beneficiaries

\footnotetext{
Address correspondence to Franciska Krings, HEC, University of Lausanne, Building Internef, Office 613, 1015, Lausanne-Dorigny, Switzerland. E-mail: franciska.krings@unil.ch

Parts of this study were presented at the $43^{\text {rd }}$ congress of the German Psychological Society in Göttingen, September 2004.
} 
because they cause them (and their colleagues) to question their competence (Steele, 1990). For proponents however, opposition to AAPs stems merely from prejudice.

Research has examined attitudes toward AAPs and their psychological basis. For organizations, identifying determinants of attitudes has direct practical implications because it shows under what circumstances AAPs can be successfully implemented. However, the vast majority of the studies on attitudes toward affirmative action have been conducted in the United States or Canada (Doverspike, Taylor, \& Arthur, 2000) and may not easily generalize to other countries. The history of discrimination, the evolution of feminism and civil rights movements, the institutionalization of gender equality, the situation of working women and minorities, and the prevalence of work policies vary greatly between countries (Appelt, 2000; Dahlerup, 1986). These socio-political factors are likely to shape attitudes toward affirmative action. Therefore, it is important to replicate findings on attitudes and their determinants that were obtained within a specific country in order to examine how these results will generalize to different contexts (e.g., Brutus, Parra, Hunter, Perry, \& Ducharme, 1998). The present study attempted to replicate and extend research on determinants of attitudes towards affirmative action for women in a Swiss context. We examined knowledge of and attitudes toward workplace AAPs for women that differed in program strength in a Swiss sample of employees. Attitudes toward AAPs are often explained in terms of individual differences of the respondents. Among those, demographic variables such as race and gender, and beliefs about the beneficiaries (prejudice) have been widely studied (Kravitz, 2004). In order to replicate prior findings, we included demographic variables (gender) and prejudice towards working women as predictors. Moreover, we extended prior research by including other individual differences measures that have not received much attention yet, namely self-views. Some studies suggest that perceptions of self (e.g., identity) are linked to attitudes towards affirmative action (Konrad \& Hartman, 2001; Little, Murry, \& Wimbush, 1998). We focused on self-esteem and gender selfconcept as important aspects of self-views likely to affect attitudes toward AAPs for women. Some analysts (e.g., Beaton \& Tougas, 2001; Konrad \& Hartman, 2001) suggest that interindividual differences on psychological dimensions such as prejudice or identity underlie gender differences in attitudes toward AAPs. These underlying processes are considered general psychological mechanisms and as such they should not depend on socio-political characteristics of a specific country. Thus, we aimed to replicate prior findings that interindividual differences on psychological dimensions (in the present study, prejudice, self-esteem and gender self-concept) mediate the relation between gender and attitudes toward AAPs. 
In the following sections, we first describe socio-political characteristics of gender equality and affirmative action in Switzerland and compare them to the United States. Then, we summarize relevant research on knowledge and determinants of attitudes toward affirmative action and outline the present study's hypotheses.

\section{GENDER EQUALITY AND AFFIRMATIVE ACTION IN SWITZERLAND}

Switzerland and the United States are both individualistic countries (Hofstede, 2001); i.e., they are culturally similar on a dimension that is important with respect to reactions toward affirmative action (Kemmelmeier, 2003). But they have different socio-political traditions and differ with respect to the situation of working women as will be described in what follows.

Demographically, Swiss women (as American women) are less likely to be found in supervisory positions and they are paid less than men (Swiss Federal Statistic Office [SFSO], 2004). Similarly to the United States, employment rates are lower for women than for men $(59 \%$ of women are employed or seeking a job compared to $76 \%$ of men). In the US, the majority (74\%) of working women works full-time. The majority (56\%) of Swiss working women, however, works part-time. When having their first child, about one third of the Swiss women working full-time start working part-time and another third stops working altogether. Among the part-time working women, about half stop working with the arrival of the first child, while the other half continue working part-time but at a reduced percentage. After having a second child, the nonworking women make up the majority $(60 \%)$, while about a third continue working part-time (Vuille, 2000). Thus, maternity represents a dramatic event in the career of Swiss women. A comparable event is neither observed in the United States nor in many other Western European countries (SFSO, 1996). For example in the United States, employment rates among mothers are much higher (55\%-73\% of mothers work, depending on the number and on the age of their children). The described career pattern of Swiss women is not always voluntary. A large percentage of women would like to work: According to the European Labor Force Survey, about $20 \%$ of the inactive Swiss women would like to work, and the percentage increases with education (Jaumotte, 2003).

The institutionalization of gender equality took place comparatively late in Switzerland and as such, Switzerland represents a rather unique case within Western nations. Women's rights movements were active since the 19th century when women formed local associations in order to further their interests. But they may not have been effective because for 
a long time, women were denied the right to vote (Sutter, 2000). Women's voting rights were established very late, in 1971. The principle of equal rights for women and men has been embodied in the Swiss Constitution since 1981, and the Federal Law on Equality between Women and Men has been only in force since 1996 (in the United States, federal equal opportunity laws have been in force since the 1960s; the Sex Discrimination Act was passed in 1975). In 1997, Switzerland was one of the last countries to ratify the UN convention of 1979 which obliges member states to establish measures to protect human and basic rights of women in political, social, economic, and cultural domains. In 2005, Switzerland was the last country in Europe to establish maternity insurance.

Goals of Swiss affirmative action in work settings are similar to those in the United Sates: They are designed to promote equality and reduce direct and indirect discrimination. One major difference from the United States is that in Switzerland, the majority of AAPs focus on women (Swiss Federal Office for Equality of Women and Men, 2004). Other groups such as ethnic minorities are rarely covered. Based on the Federal Law on Equality between Women and Men, the government funds workplace AAPs for public and non-profit organizations. Between 1996 and 2004, 303 affirmative action projects were funded. There is a great variety of AAPs in public and private organizations. They cover the continuum from opportunity enhancement like mentoring programs to preferential selection and financial incentives for organizations that hire more women. Thus, types of AAPs are similar to programs established in the United States or Canada.

Taken together, the situation of Swiss working women and Switzerland's history of the institutionalization of gender equality differ markedly from the United States. Major differences are employment rates among mothers and the time that has elapsed since the introduction of AAPs. Goals of affirmative action for women as well as types of AAPs are, however, similar. In what follows, we will turn to determinants of attitudes toward AAPs that have been identified in the literature and outline our hypotheses. Furthermore, we will discuss how the described Swiss socio-political characteristics may shape participants' responses.

\section{DETERMINANTS OF ATTITUDES TOWARD AFFIRMATIVE ACTION}

\section{Effects of AAP Strength}

Attitudes toward AAPs vary by AAP type. In fact, there are many forms of AAPs that differ with respect to the relative weighting of demographic status versus merit criteria. They can be classified on a continuum that ranges from "soft" to "hard" measures: Programs on the soft end (e.g., elimination of discrimination, opportunity enhancement 
programs) use individual merit as a primary criterion whereas programs at the hard end (e.g., hard preferential selection, quotas) use demographic status as the primary criterion in selection decisions such as hiring or promotion (Nacoste, 1990, 1996; Kravitz, 2004). There are many ways in which demographic status and merit criteria can be combined, and programs fall at different points on the continuum depending on the degree to which demographic status counts in decisions. But individuals often are unaware of this variety. They have limited knowledge about what AAPs are (e.g., Arriola \& Cole, 2001) and tend to see hard measures as typical (Heilman, Battle, Keller, \& Lee, 1998; Kravitz \& Platania, 1993). In Switzerland, affirmative action for women has only recently been introduced. Thus, we expected to find limited knowledge of AAPs, possibly even more than in American/Canadian samples (Hypothesis 1). Types of AAPs that exist in Switzerland are very similar to those in the United States. Hard measures have triggered more controversy and public attention than soft forms. Thus, we expected to replicate prior findings and find a tendency to associate AAPs with hard measures (Hypothesis 2).

AAP strength is of great relevance to attitudes toward AAPs and their psychological impact. Soft measures like passive non-discrimination or opportunity enhancement programs receive more support and are perceived as fairer than hard measures like quotas and strong preferential selection (e.g., Matheson, Warren, Foster, \& Painter, 2000; Kravitz, 1995; Kravitz \& Platania, 1993; Tougas \& Veilleux, 1988; Wagner \& Schmermund, 2000). In the present study, respondents' evaluations of different forms of AAPs were assessed. Given the similarity between types of programs in Switzerland and the United States, we expected to replicate prior findings by showing that attitudes toward hard measures will be less positive than attitudes toward soft measures (Hypothesis 3). From the perspective of distributive and procedural justice, this pattern makes sense. Hard measures and preferential treatment violate principles of people's fairness norms of resource distribution and of the procedures applied to distribute resources.

\section{Individual Differences and Attitudes toward Affirmative Action}

Women and Blacks are often more favorable toward affirmative action than men or Whites (e.g., Bobo \& Smith, 1994; Kravitz \& Platania, 1993; Matheson, Echenberg, Taylor, Rivers, \& Chow, 1994). This may reflect these groups' self-interests because they are likely to benefit from AAPs. But the mere existence of a relation between gender and attitudes does not say much about the psychological processes underlying the attitude. If both positive and negative attitudes about AAPs are to be understood, it is important to move beyond demographic group differences and explore their psychological bases. Demographic group 
membership is associated with beliefs and perceptions that may explain group differences in attitudes toward affirmative action. Some research suggests that gender differences are mediated by differences in psychological variables such as beliefs about women or about gender discrimination (Konrad \& Hartmann, 2001). We focused on three possible mediators of gender effects, namely prejudice, self-esteem and gender self-concept.

\section{Prejudice}

Racism and sexism are related to opposition to affirmative action (e.g., Little et al., 1998; Kravitz, 1995; Tougas, Crosby, Joly, \& Pelchat, 1995). Although studies suggest that overt, traditional forms of prejudice are becoming more rare, subtle forms, called symbolic or modern prejudice, still exist (Kinder \& Sears, 1981; McConahay, 1986; Swim, Aikin, Hall, \& Hunter, 1995). Contrary to traditional prejudice, symbolic prejudice is not based on beliefs about biological inferiority and inherent personality traits of a group. It represents a coherent belief system that combines negative affect with conservative ideology based on the idea that discrimination is no longer an obstacle to low status groups and thus, their disadvantages are due to their own unwillingness to take responsibility and work hard (Henry \& Sears, 2002). Similarly, symbolic or modern prejudice toward women entail the belief that women are not longer discriminated in today's society and their demands for better treatment are unjustified (e.g., Swim et al., 1995). Symbolic prejudice is also related to resistance to affirmative action (e.g., Little et al., 1989; Tougas et al., 1995). Some research suggests that symbolic prejudice mediates gender differences in attitudes towards AAPs. Across various cultural contexts, men score higher on different measures of prejudice toward women than women do (Glick \& Fiske, 2001; Eckes \& SixMaterna, 1998). Furthermore, subtle prejudice has been shown to mediate gender differences in perceived threat of AAPs for self-interests (Little et al., 1998). Similarly, disbelief in discrimination mediated gender differences in attitudes toward affirmative action for women in academia: Konrad and Hartman (2001) found that male academics held more negative attitudes toward affirmative action because they were less likely to believe that female academics experience discrimination. Disbelief in continuing discrimination is also a core element of symbolic prejudice. Thus, we expected to replicate prior findings: symbolic prejudice toward working women was expected to mediate the relation between gender and attitudes toward AAPs (Hypothesis 4).

\section{Self-esteem}

There are small but consistent gender differences in self-esteem showing that men have higher self-esteem than women (Kling, Hyde, 
Showers, \& Buswell, 1999). Self-esteem has been linked to a wide range of work and non-work attitudes (e.g., Brook, 1991). Some research demonstrates how self-esteem might also be related to attitudes towards affirmative action. Little et al. (1998) found that respondents with lower self-esteem were more likely to believe that their self-interests would be harmed by workplace AAPs. Perceptions of self-interest, in turn, are related to attitudes towards AAPs (Bobo, 1998). People tend to oppose AAPs if they see them as threatening their self-interest. Research based on social identity theory links self-esteem to prejudice which, in turn, is closely related to attitudes towards AAPs. Social identity theory posits that people favor in-group members over out-group members in order to enhance their self-esteem (Tajfel \& Turner, 1979). This notion finds empirical support, also for attitudes toward the opposite gender. For example, for men, a threat to self-esteem may result in less positive attitudes toward women (Malby \& Day, 2003). Valentine (1998) found that men with low self-esteem were more likely to support traditional sex roles and women not working than men with high self-esteem. Self-esteem has also been linked to perceived discrimination. For men, low selfesteem is associated with perceiving higher personal discrimination as well as higher discrimination of men as a group (Kobrynowicz \& Branscombe, 1997). AAPs favoring women can be regarded as measures that discriminate against men. Thus, men who feel discriminated against should be more likely to oppose AAPs for women. Taken together, these results suggest that persons with low self-esteem hold more negative attitudes towards AAPs. Consequently, we hypothesized that self-esteem mediates the relation between gender and attitudes towards AAPs (Hypothesis 5).

\section{Gender Self-Concept}

Konrad and Hartman (2001) linked aspects of identity to attitudes towards AAPs by examining the role of feminist self-identification. They argued that people who identify themselves as feminists have more positive attitudes than non-feminists and expected feminist self-identification to mediate gender differences in attitudes. Empirically, however, feminist self-identification was not linked to attitudes when the influence of other variables (e.g., belief in discrimination) was controlled. Arriola and Cole (2001) demonstrated a relation between aspects of White racial identity and associations with AAPs. They argued that Whites who feel greater comfort interacting with African Americans and feel positively about their identities as Whites are more supportive of affirmative action. Given these interesting results and the fact that the role of identity has not yet been widely studied, we included participants' gender-related self-concept as predictor of attitudes. Gender related self-concepts were operationalized as perceptions 
of gender roles; i.e., participants' self-descriptions in terms of typical feminine and masculine traits (Bem, 1981; Oswald, 2004). Typical feminine traits are traits that are considered more suitable for women than for men (e.g., nurturing, gentle). Typical masculine traits are traits that are considered more suitable for men (e.g., assertive, decisive) than for women. A person may be described as "masculine" or "feminine" (sex-typed) or androgynous; i.e., having characteristics of both. We hypothesized that gender roles mediate the relation between gender and attitudes towards AAPs (Hypothesis 6). People with more traditional, sex-typed self-concepts (e.g., men who see themselves primarily in terms of masculine and women who see themselves primarily in terms of feminine traits), might be less favorable toward AAPs because AAPs enable women to leave traditional gender roles and access positions (e.g., management positions) that are believed to require typical male traits.

In sum, in the present study, we combined structural elements of AAPs (different types of AAPs for women) with demographic (gender) and psychological factors (symbolic prejudice toward working women, self-esteem, and gender self-concept). Psychological variables were expected to mediate the relation between gender and attitudes towards AAPs. We also assessed control variables that are likely to influence attitudes. Perceived discrimination of AAP target group members can be an important predictor of attitudes (e.g., Son Hing, Bobocel, \& Zanna, 2002), so we included a measure of perceived gender equality at the workplace. We also included a control measure of perceived outcome of AAPs; i.e., perceived impact of AAPs on one's own career. Note that outcome perceptions may shape attitudes toward AAPs of men and of women. For example, women may oppose stronger forms of AAPs for women because they perceive hard AAPs as a threat to existing rules that govern the distribution of employment resources. Or they may oppose AAPs for women because they fear stigmatization of women as incompetent (Heilman, Block, \& Stathatos, 1997).

The present study focused on employees. The majority of studies on attitudes toward AAPs has worked with student samples. Although students are future workers, results obtained through them should be handled with care. Many of the issues of equality between men and women come up when experiencing work life; i.e., when being confronted with the handling of gender equality within a particular company. Moreover, a new perspective on AAPs for women might emerge with maternity because some AAPs deal with child care. Consequently, we focused on employees who had work experience, and who were employed at least half-time. And we included both parents and non-parents in our study. 


\section{METHOD}

\section{Participants}

Participants were 162 employees (46\% women) of different companies in French speaking Switzerland. They ranged in age from 20 to 63 years $(M=36.1, M d n=34.0)$. The majority $(79 \%)$ had at least two years of work experience. Three quarters of the participants worked full-time. 64 participants (48 men) were supervisors. Men and women reported similar education levels. Education was as follows: obligatory and/or professional school $(n=13)$, apprenticeship $(n=52)$, high school $(n=17)$, technical college $(n=21)$, university $(n=57)$. Two persons did not indicate their education. About a third of the participants worked in the service sector (29\%), a quarter in industry and construction (22\%), and a seventh in public service (13\%). The remaining third worked in various sectors such as health, teaching, social services, or law.

26 women and 34 men were parents (37\%). Both fathers and mothers had on average two children $(M=2.1, S D=.80)$. About a quarter of the parents had at least one child that was younger than pre-school age. The majority of the parents lived together with their partner $(88 \%)$, whereas among the non-parents, less than half lived with their partner (43\%). In most of the partnerships (79\%), both partners worked.

\section{Procedure and Measures}

Participants were approached by psychology students of the University of Neuchâtel. The study was conducted in two parts: first, participants' general knowledge of AAPs was assessed. They received a sheet of paper with a short explanation of affirmative action in work settings and which contained the following question: "When you think of AAPs for women, which concrete measures come to your mind spontaneously?". The participant noted the answer on the sheet and handed it to the student. Then, he or she received a questionnaire containing the questions and scales described below. After having filled out the questionnaire, the participant mailed it back to the University. The study was conducted in two parts in order to be able to measure participants' knowledge of AAPs independently of the information included in the questionnaire (one section of the questionnaire described different forms of AAPs).

\section{Evaluations of Different AAPs}

This section of the questionnaire contained descriptions of eight different AAPs and was constructed following Wagner and Schmermund (2000). In a pre-test of their study, participants had to evaluate six AAPs 
for women varying in the degree to which they took individual merit in a hiring decision into account. The participants considered the following four AAPs to give more weight to gender than to individual merit (in descending order): evaluating women's qualifications differently (differential evaluations), quotas for women, organizational incentives for the hiring of a woman (e.g., in form of a bonus), and preferential selection of women with equal qualifications. Special continuous education programs for women and the encouragement of women's applications were considered to give more weight to merit than gender. We included the six AAPs of Wagner and Schmermund (2000) in our study and added two more, namely the financing or provision of child care facilities and mentoring programs for women. Both are typical opportunity enhancement; i.e., soft, programs (Kovach, Kravitz, \& Hughes, 2004). With these eight programs, we intended to represent the majority of AAPs for women in Switzerland. After reading the brief description of each program, participants rated the program on four 5-point Likert-scales: positivity $(1=$ negative to $5=$ positive $)$, necessity $(1=$ superfluous to $5=$ necessary $)$, justice $(1=$ unjust to $5=$ just $)$, and goal attainment $(1=$ doesn't reach its goals to $5=$ reaches its goals $)$.

\section{Symbolic Prejudice toward Working Women}

This scale was a 4-item adaptation of Henry and Sears' (2002) Symbolic Racism 2000 scale which represents a unidimensional construct that contains four specific themes: (1) "denial of continuing discrimination" of minority groups; (2) "undeserved advantage", the belief that minorities have gotten more than they deserve; (3) "work ethic and responsibility for outcomes", the belief that the minority's failure to progress is due to its unwillingness to work; and (4) "excessive demands", the sense that minorities demand too much. The original scale contains eight items. For our scale, we reduced the number to four because not every item was applicable to Swiss working women. Moreover, items concerning work ethics were not included because they do not apply to stereotypes of working women. Thus, the items chosen represented three of the four themes whereby each theme was represented by at least one item (see Appendix). Scores were later translated into z-scores (Cronbach's $\alpha=.79$ ).

\section{Self-Esteem}

We administered a French version of Rosenberg's (1965) self-esteem scale. It contains 10 items (e.g., "I am able to do things as well as most other people"; "On the whole, I am satisfied with myself"). Participants indicate their agreement on 4-point Likert-type scales $(1=$ strongly agree to $4=$ strongly disagree) Cronbach's $\alpha$ was .80 . 


\section{Gender self-concept}

Gender self-concept was operationalized by using a 60-item French version of the Bem Sex-role inventory (Gana, 1995). The questionnaire contains 20 feminine (e.g., yielding, affectionate, loyal), 20 masculine (e.g., defends own beliefs, independent, willing to take risks) and 20 neutral (e.g., helpful, conscientious, happy) characteristics. Participants rate the extent that a characteristic describes themselves on a 7-point Likert scale $(1=$ almost never describes me to $7=$ almost always describes me). Scores characterize a person as feminine (femininity score: mean for feminine items), masculine (masculinity score: mean for masculine items), or androgynous with respect to his or her gender role. Androgyny scores are calculated by subtracting the femininity from masculinity score for each individual. Thus, a person is considered androgynous as a function of the difference between her or his endorsement of feminine and masculine personality characteristics. Androgyny scores closer to zero indicate more androgynous gender selfconcepts; i.e., androgynous people have similar scores on the masculine and feminine scales. Cronbach's $\alpha$ for femininity and masculinity was .77 and .85 respectively.

\section{Perceived Gender Equality at Work (Control Variable)}

This scale consisted of three items measuring the extent to which participants perceived that, in their organization, men and women were treated equally. Participants indicated their agreement on a 5-point Likert-type scale ( $1=$ strongly disagree to $5=$ strongly agree) with the following statements: (1) "In general, in my organization, women and men are treated equally", (2) "In general, in my organization, women have to do more than men in order to gain the same recognition"(reverse coded), (3) "In my organization, women are generally well accepted in managerial positions". Cronbach's $\alpha$ was .71.

\section{Perceived Outcome of AAPs (Control Variable)}

For each of the 8 AAPs, participants rated the extent to which they believed that the program would influence their own career $(1=$ will probably not influence my career to $5=$ will probably influence my career). These measures served as proxies for self-interest.

\section{RESULTS}

\section{Knowledge of AAPs}

When asked which concrete AAPs came to mind spontaneously, the majority of the participants responded with none $(n=93 ; 57 \%)$. The other 69 participants cited each between 1 and 7 programs. About a 
quarter cited each one (23\%), two (28\%), three (29\%), or four (19\%) programs respectively; only one person mentioned seven programs. In order to test if certain groups; i.e., women, parents, or supervisors knew AAPs better than others, we looked at the fact of having reported a program or not and conducted three $\chi^{2}$-tests. Neither women, parents, nor supervisors differed in knowledge of AAPs from men, non-parents, and nonsupervisors, respectively (all $\chi^{2} \mathrm{~s}<3.2$ ).

Altogether 183 AAPs were mentioned. They were coded for content, according to the following ten categories: measures that facilitate the balance between family and work ("day care facilities", "adapted school hours"), that facilitate women's access to management positions ("promoting management positions for women", "offering of possibilities to access positions with more responsibilities"), that promote the appreciation of women in her different roles ("appreciation of female competences", "financial acknowledgement of women's educative work"), that promote sex-blind treatment of employees ("curriculum vitae without indication of sex"), and that promote equal salaries for men and women; moreover, encouraged application, special education, preferential selection, quotas, and other. Interrater agreement of coding, assessed by comparison of $20 \%$ of the data coded by two persons, was high (Cohen's kappa $=.71)$.

$6.6 \%$ of all mentions were not at all examples of AAPs. Measures that facilitate the balance between family and work were most frequently cited (39.9\% of all mentions). Women's access to management positions as well as equal salaries constituted each $9.3 \%$ of all mentions, followed by appreciation of women (8.2\%), quotas $(6.6 \%)$, and special education (4.4\%). Preferential selection, sex-blind treatment, and encouraged application constituted each 3.3.\% of the mentions. $6.0 \%$ fell into the category of other. Taken together, two thirds of the participants did not know AAPs or cited a program that was not at all an example of AAPs. This indicates that knowledge of AAPs was very limited and supports Hypothesis 1 . Contrary to our expectation (Hypothesis 2), those participants that knew AAPs did not associate them with hard measures. Almost half of all measures mentioned were measures facilitating familywork balance. They were mostly linked to the provision of child care and the flexibilization of work and school hours. Those AAPs represent typical opportunity enhancement measures; i.e., soft AAPs. Hard measures were mentioned comparatively rarely (e.g., 12 mentions out of 183 were related to quotas).

\section{Evaluation of Different AAPs}

Participants evaluated the eight different AAPs on four scales: positivity, justice, necessity, and goal attainment. Evaluations were highly 
correlated for each measure (all $r$ s between .62 and .79), so we aggregated the four dimensions to attitude scales (for each measure, Cronbach's $\alpha$ between .78 and .88). In order to explore differences between clusters of attitudes according to structural elements of AAPs (AAP strength), we conducted an exploratory factor analysis. Through principal component analysis with Varimax rotation, three factors emerged that had eigenvalues larger than 1 and explained together $63.2 \%$ of the variance. The first factor explained $37.5 \%$ of the variance. Factor loadings showed that it was composed of attitudes towards quotas, preferential selection, organizational incentives, and differential evaluation (all factor loadings $>.62$, range of inter-item correlation .30 to .56, all $p \mathrm{~s}<.001$, average inter-item correlation .36, Cronbach's $\alpha=.72$ ). These programs fall at different points on the hard half of the continuum (Kovach et al., 2004; Wagner \& Schmermund, 2000). They involve preferential treatment and positive discrimination. The second factor explained $13 \%$ of the variance and was composed of attitudes toward encouraged application, special education, and mentoring (all factor loadings $>.62$; range of inter-item correlation .27 to .47 , all $p \mathrm{~s}<.001$, average inter-item correlations .39 , Cronbach's $\alpha=.67$ ). Those programs represent approaches to opportunity enhancement; i.e., programs that fall at different points on the soft half of the AAP-continuum (Kovach et al., 2004). The third factor explained $12.6 \%$ of the variance and consisted of attitudes toward child care (factor loading $=.86$ ). Taken together, attitudes toward hard, preferential treatment measures were clearly differentiated from attitudes toward soft, opportunity enhancement measures indicating similarities between American/Canadian and Swiss samples and supporting our assumptions. However, unlike other studies, attitudes toward child care were clearly differentiated from attitudes toward other opportunity enhancement measures despite the fact that child care measures are considered typical opportunity enhancement programs (Kovach et al., 2004). This indicates that attitudes toward AAPs are shaped by specific cultural context. We will come back to this point in the discussion.

Based on these findings, we created three attitude scores. First, we aggregated attitudes to two scores: one for attitudes toward preferential treatment/positive discriminatory programs (PT/PD: differential evaluation, preferential selection, quota, organizational incentives) and one for attitudes toward opportunity enhancement programs (OPENH: encouraged application, special education, mentoring). The third score was attitudes toward child care programs (CC). A two-factor ANOVA with AAPs (PT/PD, OPENH, CC) as within-subject and gender as betweensubject factor revealed two main effects: Women were more positive toward AAPs than men, $F(1,160)=4.7, p<.05$, and attitudes differed with respect to program type, $F(2,320)=483.3, p<.01$. These main effects 
were further qualified by an interaction, $F(2,320)=5.0, p<.01$. A simple main effect test of the interaction showed that both men and women evaluated CC ( $M=4.5, S D=.67)$ more positively than OPENH ( $M=3.3$, $S D=.87)$, and PT/PD $(M=2.2, S D=.83)$ more negatively than the other two types of programs, $F(2,320)=313.9, p<.01$, thus, confirming Hypothesis 3. Gender differences emerged for attitudes toward OPENH, $F(1,160)=4.7, p<.05$, and for attitudes toward PT/PD, $F(1,160)=8.2$, $p<.01$. Women held more positive attitudes toward both types of programs than men (women: OPENH $M=3.5, S D=.80, \mathrm{PT} / \mathrm{PD} M=2.4$, $S D=.87$; men: OPENH $M=3.2, S D=.88$, PT/PD $M=2.0, S D=.75$ ). Taken together, consistent with our expectations, attitudes were more positive toward softer than toward stronger forms of AAPs. Moreover, women were more positive toward AAPs than men, except for AAPs involving child care. Concerning child care measures, women and men held similar attitudes.

\section{Mediation Analyses}

Hypotheses 4 to 6 focused on mediators between gender and attitudes toward AAPs. Mediation was tested using the Baron and Kenny (1986) model. For mediation to be demonstrated, gender must first predict attitudes toward AAPs. Second, gender must predict the proposed mediating variable. Third, for perfect mediation, the gender to attitudes toward AAPs relation must become insignificant while the mediator is significant when both gender and the mediating variable are included together as predictors of attitudes toward AAPs. Partial mediation occurs when gender has a significant direct effect on attitudes toward AAPs in addition to the significant effect of the mediator.

Education, parenthood, supervisor status, perceived gender equality at work, and perceived outcome were entered into each of the regression equations as control variables. Correlations among all variables used are presented in Table 1. Consistent with our hypotheses, gender correlated with attitudes toward PT/PD and slightly with attitudes toward OPENH. However, it did not correlate with attitudes toward CC (for $M \mathrm{~s}$ and $S D \mathrm{~s}$, see above). Also consistent with our expectations, gender correlated consistently with the three proposed mediators. Correlations indicated that men $(M=.25, S D=.81$; z-scores $)$ scored higher on symbolic prejudice toward working women than women $\operatorname{did}(M=-.30, S D=.63$; z-scores), that men had slightly higher self-esteem $(M=3.3, S D=.37)$ than women $(M=3.2, S D=.42)$, and that men had higher androgyny scores $(M=-.01, S D=.82)$ than women $(M=-.87, S D=.85)$ showing that men were more androgynous and women were more feminine with respect to gender roles. Symbolic prejudice consistently correlated negatively with attitudes toward AAPs. Consistent with our expectations, 


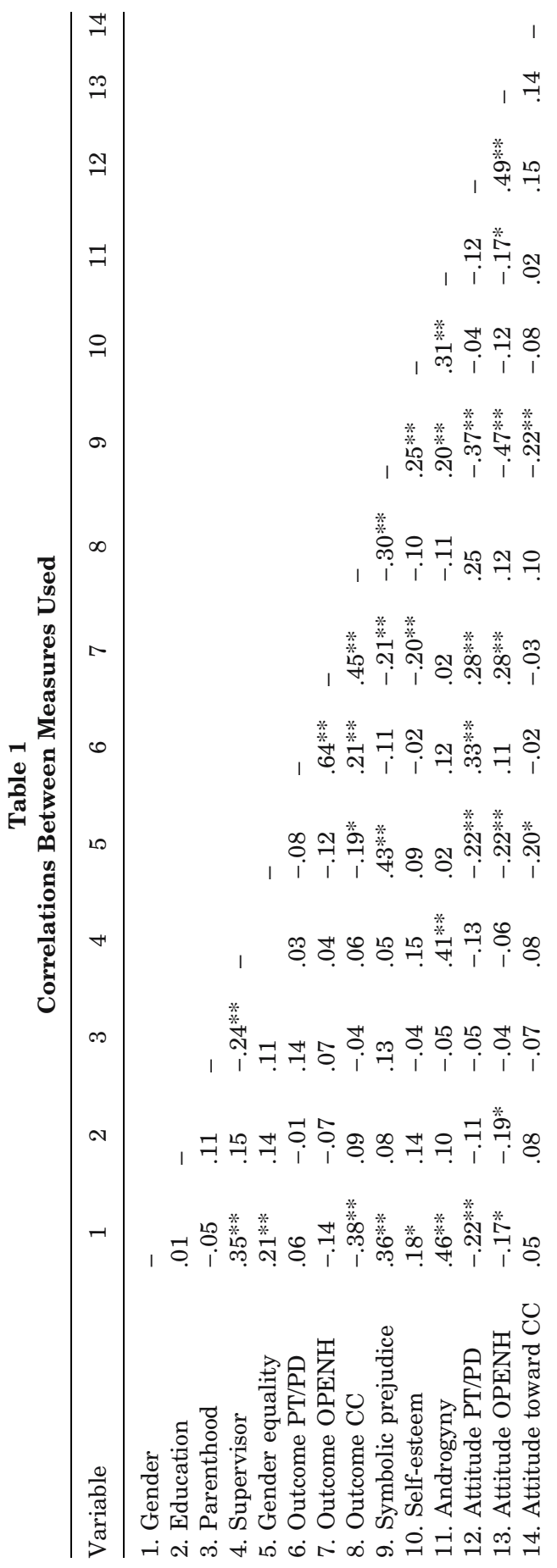

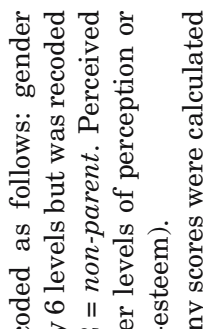

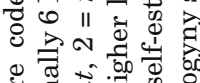

व.

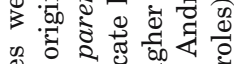

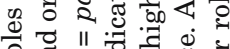

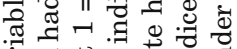

సี.

$\dot{0} \tilde{\circlearrowright}$

द्व

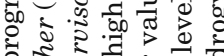

2.

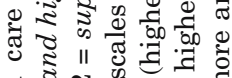

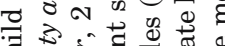

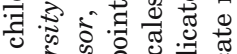

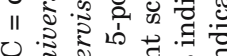

U

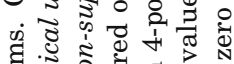

శ్

है,

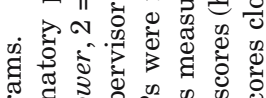

कृ.

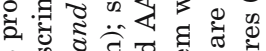

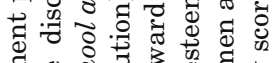

वृ.

สี

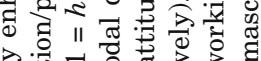

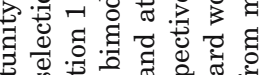

ष्य

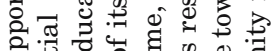

II

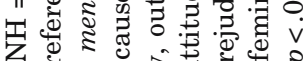

प气

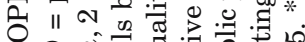

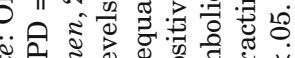

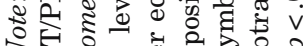

之乡

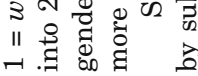


higher levels of prejudice were associated with more negative attitudes. For self-esteem, none of the correlations with attitudes toward AAPs were significant. For androgyny, only the correlation with attitudes toward OPENH was significant, showing that higher androgyny scores were associated with less positive attitudes. $68 \%$ of androgyny scores were between -1.35 et $.53(M=-.41, S D=.94)$, indicating that higher androgyny scores meant more androgynous gender roles and lower androgyny scores meant more feminine gender roles. Thus, more positive attitudes toward OPENH were rather associated with more feminine than with more androgynous gender roles. Correlations between androgyny and attitudes toward $\mathrm{PT} / \mathrm{PD}$ and $\mathrm{CC}$ did not reach significance.

Three initial multiple regressions were conducted to explore the relationship between gender and attitudes toward AAPs after controlling for education, parenthood, supervisor status, perceived gender equality and outcome. Gender predicted attitudes toward PT/PD, $\beta=-.18, p<.05$; overall model, $F(6,148)=5.7, p<.001$, adjusted $R^{2}=.15$, fulfilling the first condition for mediation. Of the five control variables, perceived outcome of $\mathrm{PT} / \mathrm{PD}(\beta=.33, p<.001)$ and perceived gender equality at the workplace $(\beta=-.18, p<.05)$ were significant predictors of attitudes toward PT/PD. Attitudes became more positive as levels of perceived influence of PT/PD on one's own career increased and as levels of perceived gender equality at one's workplace decreased. Put differently, participants were more likely to hold positive attitudes toward PT/PD when they believed that PT/PD had an impact on their own career and when they believed that women were discriminated against at their workplace.

Gender was neither a significant predictor of attitudes toward OPENH $(\beta=-.09, n s)$ nor of attitudes toward $\mathrm{CC}(\beta=.10, n s)$ when education, parenthood, supervisor status, perceived gender equality and outcome were controlled. Thus, the effect of gender on attitudes toward OPENH that became apparent in the ANOVA reported above, disappeared when controlling for the influence of the control variables. Contrary to our expectations, for attitudes toward OPENH and CC, the first condition for mediation was not fulfilled and testing of mediation effects between gender and attitudes became unnecessary. Nevertheless, results of multiple regressions originally conducted to test mediation effects between gender and attitudes toward OPENH and CC are reported below because they indicate how prejudice, self-esteem, and gender role affected attitudes independently of gender.

Of the five control variables, perceived outcome of OPENH $(\beta=.24$, $p<.01)$ and perceived gender equality at the workplace $(\beta=-.18, p<.05)$ were significant predictors of attitudes toward OPENH. Attitudes became more positive as levels of perceived influence of OPENH on one's 
own career increased and levels of perceived gender equality at one's workplace decreased (i.e., levels of perceived discrimination against women increased). For attitudes toward CC, only perceived gender equality predicted attitudes $(\beta=-.21, p<.05)$, indicating that attitudes became more positive as levels of perceived gender equality at the workplace decreased.

\section{Symbolic Prejudice toward Working Women}

Multiple regressions tested whether symbolic prejudice toward working women mediated the relation between gender and attitudes toward AAPs (see Table 2). In the first regressions, after controlling for education, parenthood, supervisor status, perceived gender equality and outcome, gender significantly predicted symbolic prejudice for all three attitude scores (all $\beta \mathrm{s}>.23, p<.001$ ) indicating that men scored higher on symbolic prejudice toward working women than women did (for $M \mathrm{~s}$ and $S D$ s, see previous paragraph). For attitudes toward PT/PD, results of the second regression indicate the mediational role of symbolic prejudice between gender and attitudes. For attitudes toward OPENH and CC, they indicate the effects of symbolic prejudice on attitudes, independently of gender (recall that gender did not affect attitudes toward

Table 2

Symbolic Prejudice toward Working Women Mediating Gender and Attitudes toward AAPs

\begin{tabular}{|c|c|c|c|c|c|c|}
\hline $\begin{array}{l}\text { Regression } \\
\text { Attitudes to }\end{array}$ & ard PT/PD & $B$ & $S E$ & $\beta$ & Adj. $R^{2}$ & $\mathrm{~F}$ \\
\hline $\begin{array}{l}1 \\
2 \\
\text { Attitudes to }\end{array}$ & $\begin{array}{l}\text { Gender } \rightarrow \text { symb. prejudice } \\
\text { Gender } \rightarrow \text { PT/PD } \\
\text { Symb. prejudice } \rightarrow \text { PT/PD } \\
\text { ard OPENH }\end{array}$ & $\begin{array}{r}.48 \\
-.14 \\
-.31\end{array}$ & $\begin{array}{l}.12 \\
.14 \\
.09\end{array}$ & $\begin{aligned} & .31 * * \\
&-.09 \\
&-.29 * *\end{aligned}$ & $\begin{array}{l}.27 \\
.21\end{array}$ & $\begin{array}{r}10.4^{* *} \\
6.9 * *\end{array}$ \\
\hline $\begin{array}{l}1 \\
2 \\
\text { Attitudes to }\end{array}$ & $\begin{array}{l}\text { Gender } \rightarrow \text { symb. prejudice } \\
\text { Gender } \rightarrow \text { OPENH } \\
\text { Symb. prejudice } \rightarrow \text { OPENH } \\
\text { ard CC }\end{array}$ & $\begin{array}{r}.42 \\
.04 \\
-.46\end{array}$ & $\begin{array}{l}.12 \\
.14 \\
.09\end{array}$ & $\begin{aligned} & . 27 * * \\
& .02 \\
&-.43 * *\end{aligned}$ & $\begin{array}{l}.27 \\
.23\end{array}$ & $\begin{array}{r}10.6^{* * *} \\
7.5^{* *}\end{array}$ \\
\hline $\begin{array}{l}1 \\
2\end{array}$ & $\begin{array}{l}\text { Gender } \rightarrow \text { symb. prejudice } \\
\text { Gender } \rightarrow \text { CC } \\
\text { Symb. prejudice } \rightarrow \text { CC }\end{array}$ & $\begin{array}{r}.35 \\
.21 \\
-.24\end{array}$ & $\begin{array}{l}.13 \\
.12 \\
.08\end{array}$ & $\begin{array}{l}.23^{* *} \\
.16 \\
-.29 * *\end{array}$ & $\begin{array}{l}.28 \\
.08\end{array}$ & $\begin{array}{r}10.7 * * \\
2.9 * *\end{array}$ \\
\hline
\end{tabular}

Note. For first regressions, degrees of freedom of $F=6$, for second regressions, degrees of freedom of $F=7$. Attitudes toward AAPs were measured on 5-point scales with higher values indicating more positive attitudes. Symbolic prejudice were z-scores, with higher values indicating higher levels of prejudice toward working women. Gender was coded as $1=$ women, $2=$ men. $\mathrm{PT} / \mathrm{PD}=$ preferential selection/positive discrimination measures. $\mathrm{OPENH}=$ opportunity enhancement. $\mathrm{CC}=$ child care.

$* p<.05 . * * p<.01$. 
OPENH and CC, thus, testing of mediation became unnecessary). For attitudes toward PT/PD, symbolic prejudice fully mediated the relationship between gender and attitudes: after controlling for the influence of the control variables, symbolic prejudice significantly predicted attitudes $(\beta=-.29, p<.01)$, whereas gender no longer did $(\beta=-.16, n s)$, thus supporting Hypothesis 4 for this attitude measure. Attitudes toward PT/ PD became more negative as levels of prejudice increased. Moreover, symbolic prejudice predicted attitudes toward OPENH $(\beta=-.43, p<.01)$ and $\mathrm{CC}(\beta=-.29, p<.01)$, after controlling for the influence of the control variables (and gender). Attitudes toward OPENH and CC became more negative as levels of prejudice increased, thus partially supporting Hypothesis 4 for these attitude measures.

\section{Self-Esteem}

Results displayed in Table 3 indicate that self-esteem was largely unrelated to attitudes toward AAPs. Moreover, gender did not reliably predict self-esteem. For attitudes toward PT/PD, gender did significantly predict self-esteem $(\beta=.18, p<.05$; men had higher self-esteem than women; for $M \mathrm{~s}$ and $S D \mathrm{~s}$, see previous paragraph) after controlling for education, parenthood, supervisor status, perceived gender equality and outcome. But the overall model was not significant, $F(6,148)=1.7$, ns.

Table 3

Self-esteem Mediating Gender and Attitudes toward AAPs

\begin{tabular}{|c|c|c|c|c|c|c|}
\hline $\begin{array}{l}\text { Regression } \\
\text { Attitudes to }\end{array}$ & rd PT/PD & $B$ & $S E$ & $\beta$ & Adj. $R^{2}$ & $\mathrm{~F}$ \\
\hline $\begin{array}{l}1 \\
2 \\
\text { Attitudes to }\end{array}$ & $\begin{array}{l}\text { Gender } \rightarrow \text { self-esteem } \\
\text { Gender } \rightarrow \text { PT/PD } \\
\text { Self-esteem } \rightarrow \text { PT/PD } \\
\text { rd OPENH }\end{array}$ & $\begin{array}{r}.14 \\
-.31 \\
.10\end{array}$ & $\begin{array}{l}.07 \\
.14 \\
.16\end{array}$ & $\begin{array}{r}.18^{*} \\
-.18^{*} \\
.05\end{array}$ & $\begin{array}{l}.03 \\
.15\end{array}$ & $\begin{array}{l}1.7 \\
4.9 * *\end{array}$ \\
\hline $\begin{array}{l}1 \\
2 \\
\text { Attitudes to }\end{array}$ & $\begin{array}{l}\text { Gender } \rightarrow \text { self-esteem } \\
\text { Gender } \rightarrow \text { OPENH } \\
\text { Self-esteem } \rightarrow \text { OPENH } \\
\text { rd child care }\end{array}$ & $\begin{array}{r}.09 \\
-.15 \\
-.04\end{array}$ & $\begin{array}{l}.07 \\
.14 \\
.17\end{array}$ & $\begin{array}{r}.12 \\
-.09 \\
-.02\end{array}$ & $\begin{array}{l}.05 \\
.09\end{array}$ & $\begin{array}{l}2.4^{*} \\
3.3^{*}\end{array}$ \\
\hline $\begin{array}{l}1 \\
2\end{array}$ & $\begin{array}{l}\text { Gender } \rightarrow \text { self-esteem } \\
\text { Gender } \rightarrow \text { child care } \\
\text { Self-esteem } \rightarrow \text { child care }\end{array}$ & $\begin{array}{r}.12 \\
.14 \\
-.15\end{array}$ & $\begin{array}{l}.08 \\
.12 \\
.14\end{array}$ & $\begin{array}{r}.15 \\
.11 \\
-.09\end{array}$ & $\begin{array}{l}.03 \\
.03\end{array}$ & $\begin{array}{l}1.7 \\
1.6\end{array}$ \\
\hline
\end{tabular}

Note. For first regressions, degrees of freedom of $F=6$, for second regressions, degrees of freedom of $F=7$. Attitudes toward AAPs were measured on 5-point scales with higher values indicating more positive attitudes. Self-esteem was measured on 4-point scales with higher values indicating higher self-esteem. Gender was coded as $1=$ women, $2=$ men. PT/ $\mathrm{PD}=$ preferential selection/positive discrimination measures. $\mathrm{OPENH}=$ opportunity enhancement.

$* p<.05 . * * p<.01$. 
Furthermore, the gender effect on self-esteem could not be replicated for attitudes toward OPENH $(\beta=.12, n s)$ and $\mathrm{CC}(\beta=.15, n s)$. Consequently, the results that gender affected self-esteem for attitudes toward $\mathrm{PT} / \mathrm{PD}$ should be interpreted with caution. Results of regression 2 showed that self-esteem was not related to attitudes toward PT/PD $(\beta=.05, n s)$, whereas gender still predicted attitudes $(\beta=-.18, p<.05)$. Thus, self-esteem did not mediate the relation between gender and attitudes toward PT/PD neither did it influence attitudes independently of gender.

Self-esteem also did not affect attitudes toward OPENH $(\beta=-.02$, $n s)$ and $\mathrm{CC}(\beta=-.09, n s)$ when controlling for the influence of the control variables (and gender; recall that men and women held similar attitudes toward OPENH and CC so mediation was no longer tested). Taken together, we found no support for Hypothesis 5 .

\section{Androgyny}

Results of the first regressions (see Table 4) showed that, after controlling for education, parenthood, supervisor status, perceived gender equality and outcome, gender significantly predicted androgyny for all three attitudes scores (all $\beta \mathrm{s}>.36, p<.01$ ). Men were more androgynous whereas women were more feminine with respect to their gender roles (for $M \mathrm{~s}$ and $S D \mathrm{~s}$, see previous paragraph). For attitudes toward

Table 4

Androgyny Mediating Gender and Attitudes toward AAPs

\begin{tabular}{|c|c|c|c|c|c|c|}
\hline $\begin{array}{l}\text { Regression } \\
\text { Attitudes to }\end{array}$ & $\begin{array}{l}\text { Variable } \\
\text { rd PT/PD }\end{array}$ & $B$ & $S E$ & $\beta$ & Adj. $R^{2}$ & $\mathrm{~F}$ \\
\hline $\begin{array}{l}1 \\
2 \\
\text { Attitudes to }\end{array}$ & $\begin{array}{l}\text { Gender } \rightarrow \text { androgyny } \\
\text { Gender } \rightarrow \mathrm{PT} / \mathrm{PD} \\
\text { Androgyny } \rightarrow \mathrm{PT} / \mathrm{PD} \\
\text { rd OPENH }\end{array}$ & $\begin{array}{r}.69 \\
-.26 \\
-.04\end{array}$ & $\begin{array}{l}.15 \\
.15 \\
.08\end{array}$ & $\begin{aligned} .36 * * \\
-.16 \\
-.05\end{aligned}$ & $\begin{array}{l}.26 \\
.14\end{array}$ & $\begin{array}{l}9.9 * * \\
4.6 * *\end{array}$ \\
\hline $\begin{array}{l}1 \\
2 \\
\text { Attitudes to }\end{array}$ & $\begin{array}{l}\text { Gender } \rightarrow \text { androgyny } \\
\text { Gender } \rightarrow \text { OPENH } \\
\text { Androgyny } \rightarrow \text { OPENH } \\
\text { rd CC }\end{array}$ & $\begin{array}{r}.70 \\
.04 \\
-.16\end{array}$ & $\begin{array}{l}.15 \\
.15 \\
.08\end{array}$ & $\begin{aligned} .38 * * \\
.02 \\
-.18^{*}\end{aligned}$ & $\begin{array}{l}.25 \\
.14\end{array}$ & $\begin{array}{l}9.4^{* *} \\
4.5^{* *}\end{array}$ \\
\hline $\begin{array}{l}1 \\
2\end{array}$ & $\begin{array}{l}\text { Gender } \rightarrow \text { androgyny } \\
\text { Gender } \rightarrow \mathrm{CC} \\
\text { Androgyny } \rightarrow \mathrm{CC}\end{array}$ & $\begin{array}{r}.71 \\
.22 \\
-.07\end{array}$ & $\begin{array}{l}.16 \\
.12 \\
.06\end{array}$ & $\begin{array}{l}.38 * * \\
.19 \\
-.12\end{array}$ & $\begin{array}{l}.25 \\
.02\end{array}$ & $\begin{array}{l}9.3^{* *} \\
1.4\end{array}$ \\
\hline
\end{tabular}

Note. For first regressions, degrees of freedom of $F=6$, for second regressions, degrees of freedom of $F=7$. Attitudes toward AAPs were measured on 5-point scales with higher values indicating more positive attitudes. Androgyny was calculated by subtracting femininity from masculinity scores. Gender was coded as $1=$ women, $2=$ men. PT/PD $=$ preferential selection/positive discrimination measures. $\mathrm{OPENH}=$ opportunity enhancement.

$* p<.05 . * * p<.01$. 
$\mathrm{PT} / \mathrm{PD}$, however, androgyny did not meet the criteria for mediation; i.e., it did not predict attitudes $(\beta=-.05, n s)$ and neither did gender ( $\beta=-.16, n s)$ after controlling for the influence of the control variables. Androgyny was neither related to attitudes toward CC $(\beta=-.12, n s)$. But androgyny did predict attitudes toward OPENH $(\beta=-.18, p<.05)$ when controlling for the influence of the control variables (and gender). As has been pointed out above, $68 \%$ of the androgyny scores varied between -1.35 and .53. So contrary to our expectations, attitudes became more positive with increasing levels of femininity. Taken together, we found no support for Hypothesis 6.

\section{DISCUSSION}

The present study was about Swiss employees' knowledge of and attitudes toward different forms of workplace AAPs for women. Results showed that knowledge of AAPs was very limited: two thirds of the respondents did not know any AAPs or named a program that was not at all an example of AAPs. This is in line with other studies (Arriola \& Cole, 2001; Kravitz \& Platania, 1993) indicating similarities between Switzerland and other countries like the United States or Canada. However, the percentage of respondents not knowing AAPs was remarkably high. Arriola and Cole (2001) found that about $40 \%$ of their sample did not know AAPs. This lower percentage might be due to the fact that they used a student sample which was politically more liberal and thus, might have been more knowledgeable with regard to affirmative action. Nevertheless, the high percentage found among the Swiss employees of our study is striking. This may be due to either lack of knowledge of AAPs or actual non-existence of AAPs within organizations. But it may also be related to the specific socio-political background. Affirmative action for women has been introduced only recently in Switzerland. Moreover, the institutionalization of gender equality took place comparatively late. So it seems likely that the limited knowledge of AAPs in our sample is also due to a general lack of familiarity with the institutionalization of gender equality in Switzerland.

Unlike other studies (e.g., Kravitz \& Platania, 1993), employees that knew AAPs did not associate them with hard measures. They strongly associated AAPs with work-family balance measures, namely child care programs. This result might again reflect a specific socio-political characteristic of the Swiss context. Child care facilities are a current concern in Switzerland. They are scarce and expensive. An estimated total of 200 '000 places in day care facilities are lacking presenting an obstacle for many women to pursue a career. The need to increase day care facilities and adapt school hours that permit full-time employment is a common 
theme in Swiss politics. Discussions around this topic may have prompted participants that knew about AAPs for women to strongly associate child care with AAPs.

Attitudes differed remarkably depending on program type. This is in line with other studies showing that attitudes become increasingly positive as more weight is accorded to individual merit and increasingly negative as they violate merit rules (e.g., Kravitz \& Platania, 1993). Participants' attitudes differed between three groups of programs: opportunity enhancement, preferential selection/positive discrimination, and child care. Men and women's attitudes were more positive toward opportunity enhancement than toward preferential selection/positive discrimination, and they were most positive toward child care. This indicates that the validity of the AAP-continuum extends, at least to some extent, to different cultural contexts. Nevertheless, the finding that attitudes toward child care were remarkably more positive than attitudes toward other opportunity enhancement measures was surprising given the fact that financing and provision of child care facilities represent typical opportunity enhancement programs (Kovach et al., 2004). This might again be related to the specific situation regarding day care facilities in Switzerland. As has already been pointed out, the lack of day care facilities is a common theme in Swiss politics. Participants may have viewed child care most positively because they considered it the most urgent measure. Aside from these considerations, attitudes toward child care may have been more positive than attitudes toward other opportunity enhancement measures because child care could be perceived as less merit violating than the other equal opportunity measures included in the study. Child care facilities do not provide women with additional competencies or knowledge that may give them unmerited advantages. Mentoring or special courses, however, can be seen as merit-violating to some extent because they may enlarge competencies and knowledge of women who may not deserve it. Moreover, child care facilities are often open to mothers and fathers, whereas mentoring programs and special courses are often exclusively offered to women.

Child care was also the only program type for which no gender differences emerged. For the other two AAP types, women's attitudes were more positive than men's, thus replicating results found in American or Canadian studies (Beaton \& Tougas, 2001; Kravitz \& Platania, 1993). However, the apparent relation between gender and attitudes almost disappeared in the presence of other factors. We hypothesized that gender effects on attitudes were mediated by prejudice and self-views, after controlling for demographic variables, perceived gender equality at one's organization and perceived outcome of AAPs. Support for this assumption was mixed. It was clearest for prejudice. For attitudes toward preferential selection/positive discrimination, symbolic prejudice 
entirely mediated the initial relation between gender and attitudes. Men were less likely to support those measures because they believed that women were no longer treated unfairly at the workplace but nowadays given unwarranted advantages. For attitudes toward opportunity enhancement and child care, the mediational role of prejudice was less clear. This was partly due to the lack of consistent gender effects on those attitudes after controlling for other demographic variables, perceived gender equality and outcome. However, prejudice had a strong unique impact on those attitudes. Thus, even though prejudice did not emerge as a consistent mediator, it was a key predictor of all attitudes. Regardless of AAP strength, high levels of symbolic prejudice toward working women were closely related to negative attitudes toward AAPs for women.

We found no support for a mediational role of self-views between gender and attitudes toward AAPs. Two aspects of self-views were studied; i.e., self-esteem and gender self-concept. Self-esteem did not mediate gender effects on attitudes nor was it related to attitudes independently of gender, thus, not supporting findings reported by Little and colleagues (1998). This might be due to differences between samples and concepts included in the studies. Little and colleagues (1998) investigated students' attitudes toward AAPs for Blacks and women whereas we assessed employees' attitudes toward AAPs for women. But we also found no support for relations between self-esteem and other predictors of attitudes toward AAPs (e.g., prejudice, perceived discrimination) as has been suggested in other research (Kobrynowicz \& Branscombe, 1997; Valentine, 1998). Thus, sample differences might not alone explain why self-esteem had no impact on attitudes toward AAPs. Further studies are necessary to clarify the relation of self-esteem with other determinants as well with attitudes toward affirmative action.

Gender self-concept did not mediate gender effects on attitudes nor did it consistently affect attitudes toward different AAPs. One isolated effect was found: gender self-concept affected attitudes toward opportunity enhancement such that higher levels of femininity were related to more positive attitudes. Femininity (and androgyny) have been related to more egalitarian views of female gender roles (Szymanski, 1993). But it remains unclear, why in the present study, femininity rather than androgyny was related to attitudes toward AAPs and why it was only related to attitudes toward opportunity enhancement. Taken together, we found little support for the assumption that gender self-concept affects attitudes toward AAPs. Evidence regarding the role of self-concept and identity for attitudes toward AAPs is scarce and results are mixed. For example, feminist identification was not related to attitudes toward AAPs (Konrad \& Hartmann, 2001) but racial identity (Arriola \& Cole, 2001). Aside from sample differences, this may be due to the specific aspects of identity studied. Arriola and Cole (2001) measured the level of 
White racial identity development that assessed also the level of comfort when interacting with Blacks. Konrad and Hartmann (2001) as well as the present study measured aspects of self-views such that they did not refer to relations between men and women. However, precisely this relational aspect of identity (e.g., the extent of how comfortable a person feels when interacting with members of the other sex) may be more important for attitudes toward AAPs than other aspects of self-view. The high explanatory power of symbolic prejudice seems to support this argument: symbolic prejudices are beliefs about others and reflect important aspects of our identity as they define us to others.

Among the control variables, perceptions of gender equality at one's organization and perceptions of AAP outcome affected attitudes toward AAPs. Men and women were more supportive of AAPs when they believed that in their organization, women were treated unfairly and when they believed that AAPs had an impact on their own careers. These findings are consistent with the notion that perceived discrimination of AAP target groups moderates attitudes, even for people who strongly believe in the merit principle (Son Hing et al., 2002). Moreover, they support the assumption that self-interest considerations drive people's attitudes toward AAPs (Bobo, 1998; Konrad \& Hartmann, 2001). However, self-interest did not influence attitudes toward all types of programs. Self-interest was unrelated to attitudes toward child care, indicating that it cannot fully explain attitudes toward affirmative action. Future research is needed to clarify under what conditions selfinterests and perceived discrimination of AAP target groups influence attitudes.

This study has its limitations. The sample was small and heterogeneous in terms of age, work experience, and organizations. Consequently, results cannot easily be generalized. On the other hand, the fact that respondents came from different companies indicates that findings are not restricted to the context of one particular organization. Another limitation is the fact that independent variables, mediators and dependent variables were measured within the same survey. As such, the present study was vulnerable to the inflation of correlations by common method variance. However, correlations between indicators were not very high, supporting our approach. Moreover, we conducted relatively strict statistical tests; i.e., regression analyses controlling for several factors. Nevertheless, the possibility of common method bias as an explanation for the results found cannot entirely be ruled out.

In sum, our results underline the crucial role of beliefs about beneficiaries, about outcomes of AAPs and about discrimination of AAP target groups as basic psychological processes underlying attitudes. Moreover, they demonstrate that knowledge of and attitudes toward AAPs are not independent of but embedded in a specific cultural context. Our results 
also have direct implications for organizations. Two seem central to us: First, when implementing or reinforcing AAPs for women, organizations should consider current concerns and the socio-political situation of the country where they operate, in order to better respond to actual needs and increase employees' support. Second, organizations should be aware of the fact that beliefs about beneficiaries shape attitudes toward AAPs. Consequently, organizations could best overcome opposition to AAPs for women by changing employees' beliefs about women. This, however, is a difficult undertaking because instead of decreasing, prejudices may simply take up new, more subtle forms. Moreover, prejudices and stereotypes tend to be automatically activated without awareness on the side of the perceiver (Greenwald \& Banaji, 1995). Thus, an appropriate approach (e.g., intervention program) to reduce prejudice within an organization should first increase employees' awareness of prejudice and their dynamics and then provide strategies to detect and reduce that prejudice.

\section{APPENDIX}

Symbolic Prejudice toward Working Women

1. Discrimination against women on the labor market is no longer a problem in Switzerland. ${ }^{1}$

2. Over the past few years, women have gotten less than they deserve on the labor market. ${ }^{1,2}$

3. Women generally do not complain as much as they should about their situation on the labor market. ${ }^{1,2}$

4. Some say that too much is done for gender equality at work. Others feel that it is not enough. What do you think? ${ }^{3}$

\section{REFERENCES}

Appelt, E. (2000). Affirmative action: A cross-national debate. In E. Appelt \& M. Jarosch (Eds.), Combating racial discrimination (pp. 1-20). Oxford: Berg.

Arriola, K. R. J., \& Cole, E. R. (2001). Framing the affirmative-action debate: Attitudes toward out-group members and White identity. Journal of Applied Social Psychology, 31, 2462-2483.

Baron, R. M., \& Kenny, D. A. (1986). The moderator-mediator variable distinction in social psychology research: Conceptual, strategic, and statistical considerations. Journal of Personality and Social Psychology, 51, 1173-1182. agree)

${ }^{1}$ This item was measured on a 4 -point Likert scale $(1=$ strongly disagree to $4=$ strongly

${ }^{2}$ This item was reverse scored.

${ }^{3}$ This item was measured on a 3 -point scale $(1=$ not enough, $2=$ just what is needed, $3=$ too much) 
Beaton, A. M., \& Tougas, F. (2001). Reactions to affirmative action: Group membership and social justice. Social Justice Research, 14, 61-78.

Bem, S. (1981). Gender schema theory: A cognitive account of sex typing. Psychological Review, 88, 369-371.

Bobo, L. (1998). Race, interests, and beliefs about affirmative action. American Behavioral Scientist, 41, 985-1003.

Bobo, L., \& Smith, R. A. (1994). Antipoverty policies, affirmative action, and racial attitudes. In S. H. Danziger, G. D. Sandefur \& D. H. Weinberg (Eds.), Confronting poverty: Prescriptions for change (pp. 365-395). Cambridge, MA: Harvard.

Brook, J. (1991). The link between self-esteem and work/nonwork perceptions and attitudes. Applied Psychology: An International Review, 40, 269-280.

Brutus, S., Parra, L. F., Hunter, M., Perry, B., \& Ducharme, F. (1998). Attitudes toward affirmative action in the United States and Canada. Journal of Business and Psychology, 12, 515-533.

Crosby, F. J., Iyer, A., Clayton, S., \& Downing, R. A. (2003). Affirmative action. Psychological data and the policy debates. American Psychologist, 58, 93-115.

Dahlerup, D. (1986). Introduction. In D. Dahlerup (Ed.), The new women's movement. Feminism and political power in Europe and the USA (pp. 1-25). London: Sage.

Doverspike, D., Taylor, M. A., \& Arthur, W. (2000). Affirmative action. A psychological perspective. Huntington, NY: Nova.

Eckes, T., \& Six-Materna, I. (1998). Leugnung von Diskriminierung: Eine Skala zur Erfassung des modernen Sexismus [Denial of discrimination: a scale measuring modern sexism]. Zeitschrift für Sozialpsychologie, 29, 224-238.

Gana, K. (1995). Androgynie psychologique et valeurs socio-cognitives des dimensions du concept de soi [Psychological androgyny and socio-cognitive values of dimensions of the self-concept]. Cahiers Internationaux de Psychologie Sociale, 25, 27-43.

Glick, P., \& Fiske, S. T (2001). An ambivalent alliance. Hostile and benevolent sexism as complementary justifications for gender inequality. American Psychologist, 56, 109118.

Greenwald, A. G., \& Banaji, M. R. (1995). Implicit social cognition: Attitudes, self-esteem, and stereotypes. Psychological Review, 102, 4-27.

Heilman, M. E., Battle, W. W., Keller, C. E., \& Lee, R. A. (1998). Type of affirmative action policy: A determinant of reactions to sex-based preferential selection?. Journal of Applied Psychology, 83, 190-205.

Heilman, M. E., Block, C. J., \& Stathatos, P. (1997). The affirmative action stigma of incompetence: Effects of performance and information ambiguity. Academy of Management Journal, 40, 603-625.

Henry, P. J., \& Sears, D. O. (2002). The symbolic racism 2000 scale. Political Psychology, 23, 253-283.

Hofstede, G. (2001). Cultures consequences. Comparing values, behaviors, institutions, and organizations across nations. Thousand Oaks, CA: Sage.

Jaumotte, F. (2003). Female labour force participation. Past trends and main determinants in OECD countries (Economics Department Working Papers, Report No. 376). Paris: OECD.

Kemmelmeier, M. (2003). Individualism and attitudes toward affirmative action: Evidence from priming experiments. Basic and Applied Social Psychology, 25, 111-119.

Kling, K. C., Hyde, J. S., Showers, C. J., \& Buswell, B. N. (1999). Gender differences in selfesteem: A meta-analysis. Psychological Bulletin, 125, 470-500.

Kinder, E. R., \& Sears, D. O. (1981). Prejudice and politics: Symbolic racism versus racial threats to the good life. Journal of Personality and Social Psychology, 40, 414-431.

Kobrynowicz, D., \& Branscombe, N. R. (1997). Who considers themselves victims of discrimination? Individual difference predictors of perceived gender discrimination in women and men. Psychology of Women Quarterly, 21, 347-363.

Konrad, A. M., \& Hartman, L. (2001). Gender differences in attitudes toward affirmative action programs in Australia: Effects of beliefs, interests, and attitudes toward women. Sex Roles, 34, 415-432.

Kovach, K. A., Kravitz, D. A., \& Hughes, A. A. (2004). Affirmative action: How can we be so lost when we don't even know where we are going? Labor Law Journal, 55, 53-61. 
Kravitz, D. A. (1995). Attitudes toward affirmative action plans directed at Blacks: Effects of plan and individual differences. Journal of Applied Social Psychology, 25, 2192-2220.

Kravitz, D. A. (2004). Affirmative action. In A. Kuper \& J. Kuper (Eds.), The social science encyclopedia (3rd ed.). Routledge: London.

Kravitz, D. A., \& Platania, J. (1993). Attitudes and beliefs about affirmative action: Effects of target and of respondent sex and ethnicity. Journal of Applied Psychology, 78, 928938.

Little, B. L., Murry, W. D., \& Wimbush, J. C. (1998). Perceptions of workplace affirmative action plans. Group and Organization Management, 23, 27-47.

Malby, J., \& Day, L. (2003). Applying a social identity paradigm to examine the relationship between men's self-esteem and their attitude toward men and women. The Journal of Social Psychology, 143, 111-126.

Matheson, K. J., Echenberg, A., Taylor, D. M., Rivers, D., \& Chow, I. (1994). Women's attitudes toward affirmative action: Putting actions in context. Journal of Applied Social Psychology, 24, 2075-2096.

Matheson, K. J., Warren, K. L., Foster, M. D., \& Painter, C. (2000). Reactions to affirmative action: Seeking the basis for resistance. Journal of Applied Social Psychology, 30, 10131038.

McConahay, J. B. (1986). Modern racism, ambivalence, and the modern racism scale. In J. F. Dovidio \& S. L. Gaertner (Eds.), Prejudice, discrimination, and racism (pp. 91-126). New York: Academic Press.

Nacoste, R. W. (1990). Sources of stigma: Analyzing the psychology of affirmative action. Law and Policy, 12, 175-195.

Nacoste, R. W. (1996). Social psychology and the affirmative action debate. Journal of Social and Counseling Psychology, 15, 261-282.

Oswald, P. A. (2004). An examination of the current usefulness of the Bem sex-role inventory. Psychological Reports, 94, 1331-1336.

Rosenberg, M. (1965). Society and the adolescent self-image. Princeton, NJ: Princeton University Press.

Son Hing, L. S., Bobocel, D. R., \& Zanna, M. P. (2002). Meritocracy and opposition to affirmative action: Making concessions in the face of discrimination. Journal of Personality and Social Psychology, 83, 493-509.

Steele, S. (1990). The content of our character: A new vision of race in America. New York: HarperCollins.

Sutter, E. (2000). Frauen, Macht, Geschichte. 1848-2000. [Women, power, history. 18482000]. Bern: Eidgenössische Kommission für Frauenfragen.

Swim, J. K., Aikin, K. J., Hall, W. S., \& Hunter, B. A. (1995). Sexism and racism: Oldfashioned and modern prejudices. Journal of Personality and Social Psychology, 68, 199-214.

Swiss Federal Office for Equality of Women and Men (2004). Egalité des chances dans la vie professionnelle. [Equal chances in the professional domain]. (Report 2004). Bern: Swiss Federal Office for Equality of Women and Men.

Swiss Federal Statistic Office (1996). Herausforderung Bevölkerungswandel. Perspektiven für die Schweiz. [The challenge of demographic change. Perspectives for Switzerland]. (Statistics of Switzerland, Report No.1). Bern: Swiss Federal Statistic Office.

Swiss Federal Statistic Office (2004). Auf dem Weg zur Gleichstellung? [On the road to equality?] [Brochure]. Neuchâtel: Swiss Federal Statistic Office.

Szymanski, L. (1993). Gender role and attitudes toward rape in male and female college students. Sex Roles, 29, 37-57.

Tajfel, H., \& Turner, J. C. (1979). An integrative theory of intergroup conflict. In S. Worchel \& W. G. Austin (Eds.), The social psychology of intergroup relations (pp. 33-47). Monterey, CA: Brooks/Cole.

Tougas, F., Crosby, F., Joly, S., \& Pelchat, D. (1995). Men's attitudes toward affirmative action: Justice and intergroup relations at the crossroads. Social Justice Research, 8, 57-71.

Tougas, F., \& Veilleux, F. (1988). The influence of identification, collective relative deprivation, and procedure of implementation on women's responses to affirmative action: A causal modelling approach. Canadian Journal of Behavioral Science, 20, 16-29. 
Valentine, S. (1998). Self-esteem and men's negative stereotypes of women who work. Psychological Reports, 83, 920-922.

Vuille, A. (2000). Maternité, mariage et divorce dans les années 90 : Quelles conséquences sur la vie professionnelle des femmes? Une étude basée sur l'enquête de la population active. [Maternity, marriage, and divorce in the 90ies : What are the consequences for women's professional lives? A study based on the survey of the active population] (SakeNews No. 4). Neuchâtel: Swiss Federal Statistic Office.

Wagner, U., \& Schermund, A. (2000). Einstellungen zu Massnahmen der beruflichen Gleichstellung [Attitudes toward affirmative action measures at work]. Zeitschrift für Arbeits- und Organisationspsychologie, 44, 83-95. 